\title{
SISTEMA DE CASOS Y ANÁLISIS DEL DISCURSO ${ }^{1}$
}

\author{
Lourdes Molero de Cabeza
}

\begin{abstract}
RESUMEN
En este trabajo se presentan los resultados de una investigación en la cual se analiza el nivel actancial de un corpus constituido por relatos orales, discurso publicitario y titulares de las páginas de sucesos de periódicos venezolanos. El análisis se lleva a cabo aplicando el marco teórico y metodológico del sistema de casos de la semántica de B. Pottier $(1992,1993)$, de acuerdo con las siguientes categorías: a) relaciones iuirercasuales; b) eje de la actancia dividida en i) zona del núcleo, ii) zona del antes y iii) zona del después; c) eje de la dependencia. Los resultados indican diferencias en cuanto a la zona actancial focalizada por cada tipo de discurso. Se demuestra también que el sistema de casos de la semántica es adecuado para el estudio de las relaciones actanciales en los diferentes niveles de complejidad discursiva, desde un titular hasta un texto completo.
\end{abstract}

\section{ABSTRACT}

This article presents the results of a research in which the ACTANTIAL LEVEL of a corpus constituted by oral narratives, the discourse of advertising and headlines on the daily events of Venezuelan newspapers. The analysis was carried out following the theoretical and methodological frameword B. Pottier's $(1992,1993)$ semantic case system and according to the following categories: a) intercase relationships; b) ACTANTIAL AXIS divided into i) nucleus, ii) area of "before" and iii) area of "afterwards"; c) DEPENDENCE AXIS. The results show differences in the ACTANTIAL AREA focused in each type of discourse. The semantic case system is also shown to be adequate to study the ACTANTIAL RELATIONS at different of discourse complexity, from a headline to a complete text.

\section{Introducción}

El análisis del discurso es un campo de estudio interdisciplinario, que ha surgido a partir de algunas otras disciplinas de las ciencias humanas, como la lingüística, los estudios literarios, la antropología, la semiótica y la sociología. El desarrollo del moderno análisis del discurso tuvo sus inicios en los años sesenta y a cumienzos de los setenta; sin olvidar que ya desde 1952, Harris había intentado una definición de discurso. Durante la última década se ha observado un creciente aumento de los trabajos y publicaciones en esta nueva disciplina del texto. 
En este artículo se presentan los resultados de una investigación que tuvo como finalidad la aplicación de la Teoría Semántica de los Casos desarrollada por Bernard Pottier (1987, 1993) en el análisis de tres muestras: a) Un relato oral de una etnia indígena venezolana, la etnia wayuu. b) Titulares de las páginas de sucesos de cuatro periódicos venezolanos. c) Títulos y eslóganes de anuncios publicitarios.

Se trató de indagar cómo se comporta una teoría semántica que ha sido aplicada en el estudio actancial de la oración, cuando es utilizada en unidades discursivas más extensas -el caso del relato-, o con diferentes finalidades -el caso del discurso periodístico y del discurso publicitario-.

Se tomó como punto de partida e hipótesis de trabajo la idea de que cada discurso focaliza una determinada zona actancial del modelo, dependiendo esto del tipo de discurso, de sus objetivos y características.

\section{Principios teórico-metodológicos}

\subsection{Las teorías de casos}

Lingüistas eminentes como Hjelmslev (1935, 1937), Jakobson (1936) y Pottier (1955, 1987,1993 ) han hablado extensamente de los casos. La teoría de Fillmore y sus revisiones posteriores han jugado, a partir de 1968, un papel determinante en el desarrollo de los trabajos sobre la semántica, la sintaxis y la morfología de las relaciones actanciales. La noción de caso semántico o de "rol" ha conocido tratamientos más o menos divergentes. Tres cuestiones han llamado particularmente la atención de los investigadores: en primer lugar, los criterios de reconocimiento de los casos semánticos y su eventual jerarquización (la caracterización de los roles de "agente" y "experimentador", en particular, ha suscitado controversias profundas); en segundo lugar, el estatus de los roles en un modelo generativo y, por último, el lugar que se le asignaría a las hipótesis localistas en la definición de los roles.

Al mismo tiempo, los lingüistas funcionalistas han utilizado la noción de caso semántico en el estudio tipológico de las condiciones de acceso de los roles semánticos, en las funciones sintácticas de sujeto y objeto y en los sistemas de marcas casuales. Por su parte el cognitivismo ha desarrollado una concepción integrada de los roles en el lenguaje, en tanto que proceso cognitivo ligado a la percepción y al razonamiento. Los ejemplos de esta corriente serían la "dinámica de las fuerzas" de Talmy y su reinterpretación en el cuadro de la "semántica conceptual" de R. Jackendoff.

\subsection{El sistema casual de la semántica de Pottier}

El sistema casual de la teoría de Bernard Pottier (1987, 1993) establece la distinción entre el nivel conceptual (en el que pueden delimitarse zonas) y el nivel lingüístico, que corresponde al de una lengua natural determinada. Esta teoría toma como punto de partida un esquema que presenta las relaciones intercasuales: 
Figura 1

Las relaciones intercasuales

(Pottier 1993: 145)

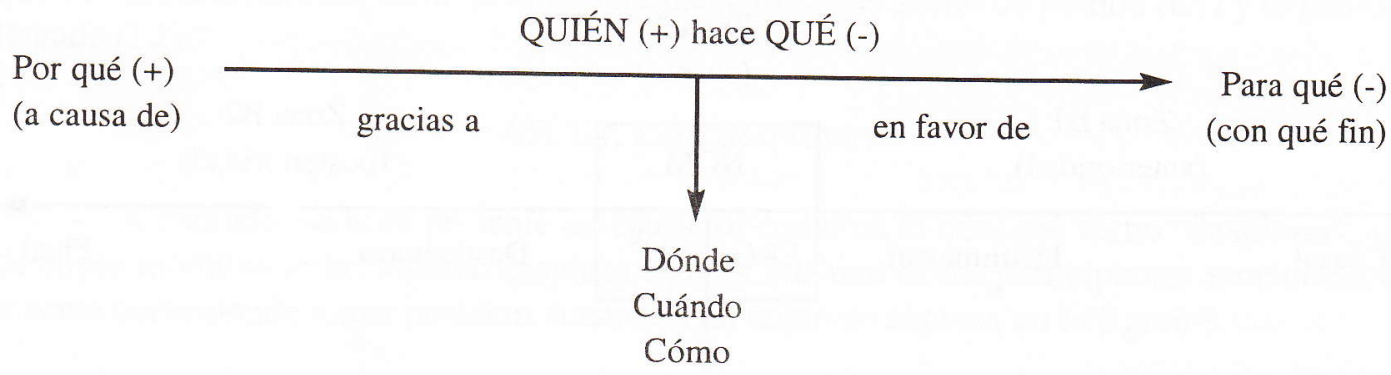

Los actantes pueden concebirse según Pottier (1992: 162), como "cumplidores de un cometido en el eje de la actancia, o colocarse en una posición marginal en el eje de la dependencia".

Figura 2

La actancia y la dependencia

(Pottier 1992: 162)

Núcleo

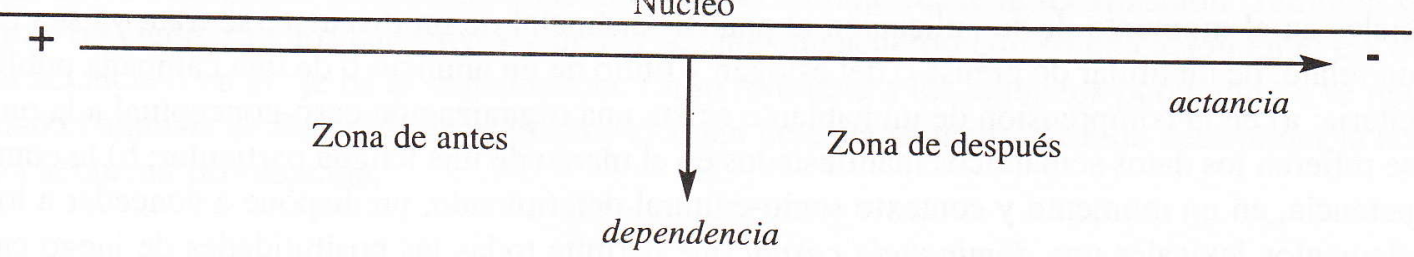

Este esquema corresponde a una estructuración organizada alrededor del "nudo casual" o "núcleo", donde se oponen los roles actanciales del ERGATIVO y del ACUSATIVO y donde se sitúa también el NOMINATIVO que expresa un rol casual neutro. El ERGATIVO (ERG) es el caso del actante dotado de una potencia semántica capaz de causar una transformación en el ACUSATIVO (ACU). El NOMINATIVO (NOM), por su parte, sería el caso del no-evento, sin diferencia de potencial. Veamos algunos ejemplos:

- $\quad$ Pedro es dichoso.

(NOM)

- $\quad$ Miguel rompió el jarrón.

(ERG) (ACU)

La zona anterior al núcleo es una zona de potencia $<+>$ : causa, origen, condición, instrumento... Lo posterior al núcleo es una zona de petencia <->: destino, objetivo, finalidad, consecuencia... Esta teoría concibe dos puestos en la zona anterior al núcleo o "zona del antes" y dos en la zona posterior o "zona del después". 
Figura 3

Las zonas caso-conceptuales

(Pottier 1992: 164)

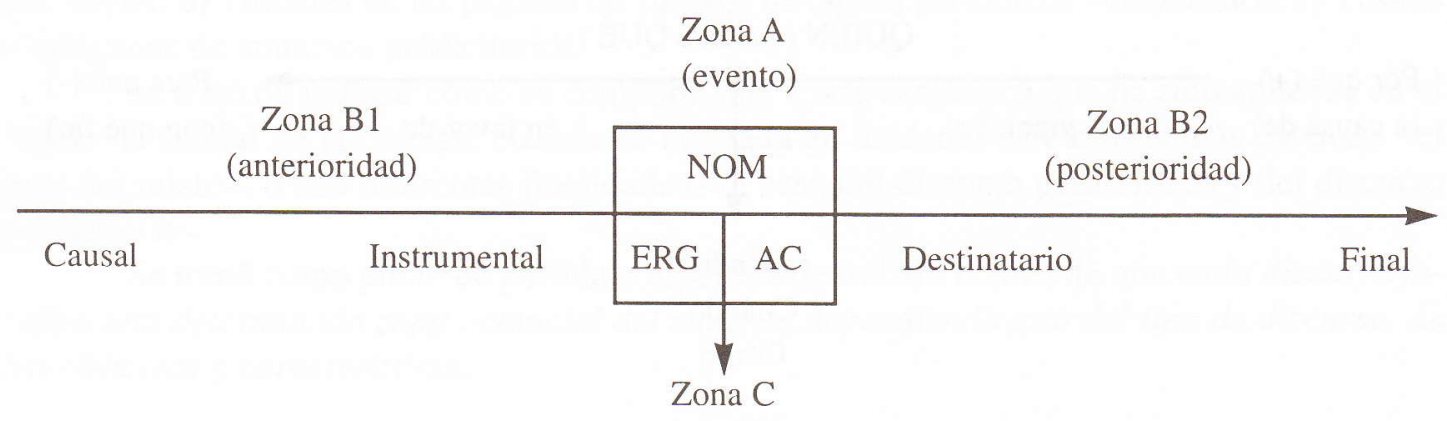

(locativos)

Un aspecto muy interesante de esta teoría para su aplicación en el análisis del discurso es la distinción entre dos tipos de actantes: los que se sitúan en el eje de la actancia primaria (eje horizontal) y que cumplen un rol determinado en dicho eje y los que se colocan en una posición marginal o eje de la dependencia (eje vertical) (véase el gráfico No. 3).

De este esquema teórico-metodológico, interesa anotar algunos aspectos que son cruciales en el momento de su aplicación al análisis actancial de un discurso, se trate ya sea de un relato, de un titular de prensa o del eslogan y título de un anuncio o de una campaña publicitaria: a) en la comprensión de un hablante existe una organización caso-conceptual a la que se refieren los datos semánticos manifestados en el marco de una lengua particular; b) la competencia, en un momento y contexto socio-cultural determinado, predispone a conceder a los elementos lexicales una dominancia casual que permite todas las posibilidades de juego casual por parte del locutor; c) todas las lenguas poseen un número " $n$ " de casos lingüísticos ligados a una morfología distintiva. Dada la estructura del español se pueden considerar los siguientes casos lingüísticos: causal, instrumental y agentivo (zona de la anterioridad); nominativo y acusativo (zona del evento); dativo, benefactivo y final (zona de la posterioridad) y los locativos (espacial, temporal y nocional) de la zona C (Pottier 1992: 167).

También en la semántica de Pottier se consideran tres estatutos (estativo, evolutivo y causativo), que son aplicados en el análisis para estudiar el comportamiento y las relaciones de los actantes en los diferentes eventos que conforman la narración.

$$
\begin{aligned}
& A \longleftarrow \alpha \quad \text { Estativo (El actante A en el estado } \alpha) \\
& \left\{\begin{array}{l}
A \longleftarrow \alpha \\
A \longleftarrow \beta
\end{array} \mid \text { Evolutivo (El actante A pasa del estado } \alpha \text { al estado } \beta\right. \text { ). }
\end{aligned}
$$

CAU $\left\{\begin{array}{c|c}A \leftarrow \alpha & \text { Causativo (El actante CAU es la causa inmediata de la transformación } \\ A \longleftarrow \beta & \text { del actante A). }\end{array}\right.$ 
Otro aspecto de la semántica de Pottier utilizado en esta investigación es el concepto de módulo actancial, entendido como un esquema que contiene los participantes semánticos (actantes) necesarios de un lexema. Así por ejemplo, en el verbo "desplazarse" el mínimo requerido semánticamente sería: el objeto desplazado (E), el punto de partida (L1) y el punto de llegada (L2):

\section{//E, L1, L2//: desplazarse}

A menudo, se hace presente un causador como en el caso del verbo "desplazar", uno de cuyos módulos sería "alguien desplaza algo". Cada uno de los participantes semánticos del lexema corresponde a una posición actancial, tal como se expresa en la figura 3.

\subsection{Las relaciones intercasuales y el análisis del discurso}

Presentados los principios teórico-metodológicos que fundamentan el estudio se pasa ahora a explicar cómo han sido aplicados. En el caso de los titulares de prensa se procedió a elaborar un análisis de las zonas actanciales para determinar cuáles son las más frecuentes. Este análisis se acompañó con el estudio de los temas -a los cuales se refieren los titulares-, de los estatutos (estativo, causativo, evolutivo) y de los tipos de verbos.

En el caso del relato se procedió al estudio del nivel actancial, tratando de determinar sobre cuál de las zonas caso-conceptuales del modelo recae la focalización. También se hizo un análisis de los causativos y de los actantes de acuerdo con su ubicación en el eje de la actancia o en el eje de la dependencia. En lo referente a los anuncios publicitarios se realizó el análisis de los casos en el título y eslogan de cada anuncio, a fin de determinar la zona actancial privilegiada.

\section{La muestra}

Para el estudio del relato se seleccionó una versión del mito del "viaje al más allá" de los guajiros, un pueblo que habita en la región noroccidental de Venezuela y nororiental de Colombia. Esta versión fue publicada por Miguel Ángel Jusayú en 1994 bajo el título de Relato de un hombre cuya mujer murió.

Para el estudio de los titulares de prensa se seleccionaron titulares de la última página o página de sucesos de cuatro periódicos venezolanos: La Columna y Panorama (periódicos de provincia, publicados en la ciudad de Maracaibo), El Universal y El Nacional (periódicos publicados en Caracas). La muestra se recogió durante tres semanas y se obtuvieron unos trescientos titulares.

Para el estudio de los titulares y eslóganes de los anuncios publicitarios se seleccionaron 45 anuncios que recogen publicidad de servicios y de productos. Los dominios a los cuales pertenecen son los siguientes: líneas aéreas, automóviles, relojes, cigarrillos, alimentos y joyas. 


\section{Resultados del análisis}

\subsection{Nivel actancial en una versión del mito guajiro del viaje al más allá}

El Relato de un hombre cuya mujer murió de Miguel Ángel Jusayú, como ya se anotó, es una versión del mito -que según el antropólogo francés M. Perrin-, es el más conocido de los guajiros: el viaje al más allá. Se trata, quizás, de la versión más completa hasta ahora conocida del mito wayuu. El pueblo guajiro es una etnia cuyos orígenes se pierden en la prehistoria del continente. Habitan en el norte de la América del Sur, en una planicie semi-desértica que se adentra en el Mar Caribe, dividida entre dos países -Venezuela y Colombia-. Diversos estudios han afirmado que este pueblo forma parte de la familia arahuaca (arawaca) por sus características lingüísticas, etnológicas y hasta por evidencias arqueológicas.

El relato seleccionado narra la historia de un guajiro que es conducido al más allá por su mujer que había muerto hacía algún tiempo. La narración en su totalidad fue dividida en cinco secuencias (Molero 1994: 100):

I. Un indio guajiro se queja excesivamente de la muerte de su mujer. Esta viene a encontrarlo en la tierra y lo conduce a Jepira, el lugar de los muertos.

II. Allí el guajiro se queda cierto tiempo con su esposa. Esta desaparece al cometer el guajiro una falta. El hombre decide partir.

III. Entonces se equivoca de camino. Vaga durante un tiempo y llega a los dominio de Ma'leiwa, a quien satisface en muchas pruebas. Pero, por no haber tomado en cuenta un consejo del viejo, es expulsado por la mujer de éste.

IV. Llega a casa del murciélago y después de aprender a tejer es ayudado a regresar a la tierra.

V. El guajiro cuenta su aventura, a pesar de las recomendaciones de quien lo ayudó a volver. Muere.

Al basarnos en la teoría de casos, lo primero que se observa es que en el relato existen actantes cuyo rol se sitúa en el eje de la actancia principal y otros situados en una posición menos importante, a veces marginal, sobre el eje de la dependencia.

Las zonas actanciales del relato pueden ser explicadas con la ayuda del siguiente esquema:

Figura 4

Las zonas actanciales en el relato

ZONA B 1

ZONA A

ZONA B2

+ ANTES

- El guajiro

DESPUÉS -

- Ma’leiwa

CAUSA

(el deseo de ver a su mujer)
- la mujer yoluja

- la mujer de Ma'leiwa

- el murciélago

ZONA C

- los familiares

- el joven mensajero
CONSECUENCIA

(la muerte) 


\subsubsection{Los actantes de la zona A o zona del evento}

En esta zona se han situado cinco actantes. Cuatro de ellos (la mujer-yoluja, Ma'leiwa, la mujer de Ma'leiwa y el murciélago) pueden ser asimilados a la esfera del ERGATIVO porque están dotados de potencia (+) y causan una transformación o están en el origen de los desplazamientos del otro actante de esta zona, que es el guajiro o actante-sujeto del relato. Gracias a este último se logra la unidad en la historia, además de que todos los eventos están de una u otra manera relacionados con él. Es también el actante que sufre una transformación $(\alpha \leftarrow \beta)$. En esta zona se situarían los actantes que Perrin (1980: 206) ha denominado "pasadores" -del francés passeur-; se trata de los actantes cuya función consiste en hacer pasar al guajiro de una región a otra. En el caso del relato que nos ocupa, los intermediarios son, en sentido estricto, el murciélago, la araña y la ranita. La acción de los intermediarios ocupa el lugar de un causativo, tal como se representa aquí:

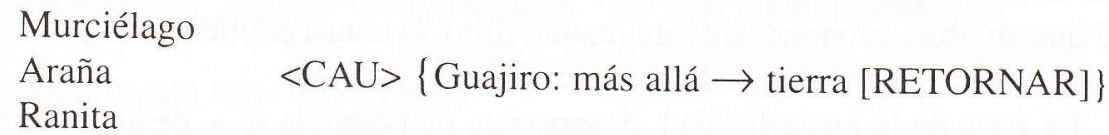

Los otros actantes situados en esta zona son:

a) La mujer muerta o mujer-yoluja: este actante conduce al guajiro desde la tierra hasta el más allá.

Mujer-yoluja $<$ CAU $>\{$ Guajiro:tierra $\rightarrow$ más allá $[$ PARTIR] $\}$

b) El dios Ma'leiwa: al comenzar la tercera secuencia el lector tiene la idea de que el guajiro por sus propios medios llegó donde Ma'leiwa. Sin embargo, este tipo de relato es exhaustivo en la presentación de los causantes; de manera que más adelante, en la misma secuencia, se lee:

Para que lo sepas ahora, tú no has venido por tu cuenta hasta aquí a donde mí. Fue como si yo te hubiese halado de allá de donde la presencia de los espectros (Jusayú 1994: 125).

Esto puede representarse así:

Ma'leiwa $<$ CAU $>$ \{Guajiro:más allá $\rightarrow$ casa de Ma'leiwa [LLEVAR] $\}$

c) La mujer de Ma'leiwa: en la versión analizada los personajes de Ma'leiwa y de su mujer cumplen las mismas funciones de los personajes Juya' y Pülowi de otras versiones del mito. La mujer de Ma'leiwa es otro causativo que por ser un actante dotado de potencia <+> está en el origen del desplazamiento a un nuevo espacio.

Ella miró al hombre, no esperó nada para lanzarle en contra un fortísimo viento que sonó "juu". El viento lo hizo volar, lo llevó a gran altura del suelo y cayó lejos (Jusayú 1994: 135). 
Mujer de Ma'leiwa <CAU> \{ Guajiro: casa de Ma'leiwa $\rightarrow$ casa del Murciélago [DESPLAZAR]\}

Este esquema corresponde al núcleo del módulo de desplazar: // E1<+>, E2<->, L1, L2// (Pottier 1993: 125) donde: E1<+> es el causador, E2<-> es el actante desplazado y L1 y L2 señalan el punto de partida y el punto de llegada.

\subsubsection{Los actantes de la zona de la anterioridad y de la posterioridad}

Estas dos zonas representan dos fases del proceso que aparece en la figura 1: el origen (a causa de) y la consecuencia (con qué fin). La zona de la anterioridad al nudo es la zona marcada con potencia $\langle+>$. La zona de la posterioridad, situada a la derecha del nudo, es una zona desprovista de potencia <-> (Pottier 1987: 117). La primera zona es un ANTES que contiene la causa que provoca el evento más importante, en este caso el viaje. En este relato, al igual que en otras versiones de este mismo mito, la causa explícita, origen del recorrido realizado por el héroe, es el deseo de ver a su mujer.

La zona de la posterioridad, desprovista de potencia $<->$, de acuerdo con el esquema teórico, presenta las consecuencias del proceso. Una vez cumplidos todos los avatares y peripecias del viaje se obtienen las siguientes consecuencias: a) conocimiento del más allá. b) transmisión de la técnica del tejido al pueblo wayuu y c) la muerte.

Hay que señalar que el relato solo hace explícitas la segunda y tercera consecuencia. La primera, que corresponde al conocimiento del más allá, es una consecuencia que debe ser inferida por el receptor. Por otra parte el relato no concede mucha importancia a la zona caso-conceptual de las consecuencias; se observa que sólo dedica a esta parte dos párrafos, de un total de cincuenta y dos que constituyen el relato total.

En el análisis actancial de este relato se ha hecho evidente que las zonas focalizadas corresponden a la zona de la anterioridad (zona B1) y a la zona de evento o núcleo (zona A).

Figura 5

Zonas focalizadas en el relato

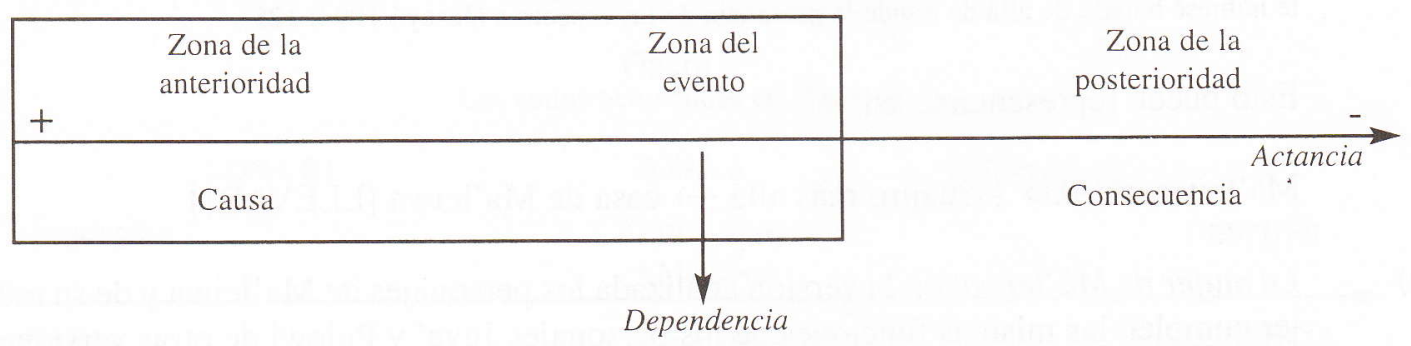

\subsection{Nivel actancial en los titulares de prensa}

Dada la gran variedad de titulares seleccionados, el primer paso consistió en identificar los ejes temáticos fundamentales a los cuales remitían las noticias de las páginas de sucesos. Se 
car los ejes temáticos fundamentales a los cuales remitían las noticias de las páginas de sucesos. Se establecieron así cinco núcleos: privación de la vida, privación de la libertad, privación de la propiedad, inseguridad y hechos de corrupción. El primer núcleo incluyó titulares referidos a asesinatos, suicidios y muertes accidentales. El segundo incluyó detenciones y secuestros. El tercer núcleo se refirió a robos, decomisos y hurtos. En el grupo de los titulares relativos al tema de la inseguridad figuran agresiones y problemas de seguridad industrial. El último núcleo abarcó los hechos de corrupción.

La mayor parte de los verbos utilizados en los titulares (detener, herir, rastrear, abalear, estrellarse, desmantelar, morir, matar, robar, suicidarse, recuperar, identificar, fugarse, capturar, asesinar, decomisar, reconocer, estrangular, atentar, localizar, investigar, ultimar, chocar, estafar...) ponen en evidencia el predominio de módulos actanciales regidos por verbos con dos actantes $(73,96 \%)$, seguidos por módulos con un solo actante $(22,18 \%)$ y con tres actantes $(3,86 \%)$. Esto indica que los módulos actanciales más usuales en los titulares de la página de sucesos son del tipo: "alguien-verbo-algo" o "alguien-verbo-a alguien". He aquí algunos ejemplos:

- Comando armado roba 90 millones.

- Ex-gerente bancario estafa 18 millones de bolívares.

- 30 hombres armados secuestran a un ganádero.

- Hampones asesinaron al ex-grande liga Gustavo Polidor.

- Policía de Sucre captura a doble homicida.

\subsubsection{Las zonas actanciales en los titulares de prensa}

El análisis de los titulares seleccionados, arrojó lo siguiente: la zona del evento es la más focalizada, pues alcanza el $80,64 \%$, seguida por la zona de la anterioridad con un $15,33 \%$ y por la zona de la posterioridad con un $4,04 \%$.

De los casos de la zona A, el mayor porcentaje le correspondió al NOMINATIVO $(61,10 \%)$, seguido por el ACUSATIVO (45,13\%) y por el ERGATIVO (18,9\%).

De los casos de la zona de la anterioridad, el que con mayor frecuencia aparece es el causal y los periódicos con mayor porcentaje de utilización son El Universal (periódico de circulación nacional) (23,33 \%) y La Columna (periódico de circulación regional) (13,43\%). Veamos algunos ejemplos de cada periódico:

\section{LA COLUMNA}

- Encadenó a su hijo porque no quería estudiar.

- Golpearon a policía porque recuperó camioneta robada.

- Cinco heridos graves por incendio en el Puerto.

\section{EL UNIVERSAL}

- Acusan a efectivo de la G.N. por la muerte de un motorizado.

- Detenido funcionario de PTJ por borrar información de las pantallas.

- Interrogados varios testigos por caso de extorsión.

La aplicación del modelo de las zonas caso-conceptuales a los titulares de prensa arrojó como resultado que la zona actancial focalizada corresponde a la zona del núcleo o del evento (zona A), tal como se observa en el siguiente gráfico: 
Figura 6

Zona focalizada en los titulares de prensa

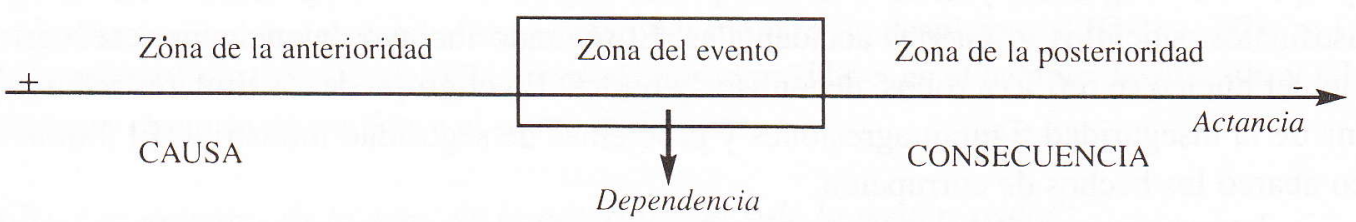

\subsection{Las zonas actanciales en los títulos y eslóganes de anuncios publicitarios}

En los anuncios publicitarios, el análisis arrojó los siguientes resultados: la zona del evento es la más representada pues obtuvo un 91,11\% correspondiendo el mayor porcentaje al NOMINATIVO; seguida por la zona C (LOCATIVO NOCIONAL, ESPACIAL Y TEMPORAL) con un 55,55 \%, correspondiendo el mayor porcentaje al LOC. NOCIONAL. Entre los ejemplos pueden anotarse los siguientes:

- "Una parte importante de la hospitalidad suiza es su toque creativo" (NOM / LOC. NOC.).

- $\quad$ "Century, joven para ser atrevido, maduro para ser precavido" (NOM./FIN.).

Por su parte la zona de la anterioridad aparece débilmente presentada con un 6,6\% y la zona de la posterioridad alcanzó un 13,33\%.

En el caso de los eslóganes la zona focalizada coresponde a la zona del evento o núcleo en un cien por ciento de los ejemplos analizados. Los eslóganes más comunes en la muestra son del tipo:

- Monza. Acelera la emoción” (NOM./ACUS.), (publicidad de un automóvil).

- Astor. Una nueva dimensión en suavidad" (NOM./NOM.), (publicidad de un cigarrillo).

En el siguiente gráfico se observan las zonas focalizadas en los títulos y eslóganes de los anuncios publicitarios:

Figura 7

Zonas focalizadas en los títulos de los anuncios publicitarios

\begin{tabular}{ll|c|c}
\cline { 3 - 3 } $\begin{array}{l}\text { Zona de la } \\
\text { anterioridad }\end{array}$ & $\begin{array}{c}\text { Zona del } \\
\text { evento }\end{array}$ & \multicolumn{2}{c}{$\begin{array}{c}\text { Zona de la } \\
\text { posterioridad }\end{array}$} \\
\hline+ & & & \\
CAUSA & & CONSECUENCIA & Actancia \\
& & &
\end{tabular}




\section{Conclusiones}

La aplicación de la teoría de casos en el relato guajiro, en los titulares de prensa y en los títulos y eslóganes de anuncios publicitarios permite anotar las siguientes conclusiones:

a. El relato tiene tendencia a explicitar las causas de los eventos narrados, lo cual conduce a la focalización de la zona de la anterioridad (zona B1).

b. Dedica la mayor parte de la narración a la presentación de las diferentes acciones que se sitúan en la zona del evento, sobre todo a aquellas realizadas por el actante principal o héroe. Esto indica que se privilegia, además, la zona A o del evento.

c. Las características que confiere a ese actante principal -que es el hilo de la narración porque todos los eventos se refieren a él de una u otra manera- hace posible que lo asimilemos, en algunos pasajes de la narración, a la esfera de caracterización del NOMINATIVO conceptual, y en otros, a la esfera de caracterización del ACUSATIVO conceptual. En el primer caso, sería el actante que se desplaza de la tierra al más allá para retornar de nuevo a la tierra. Sería el caso del actante viajero. No en balde, en una clasificación de los relatos guajiros (Molero 1993: 125-38) propusimos hablar de los relatos en los que predomina el macro-evento viaje. En otros apartados de la narración este mismo actante se asimila más claramente al ACUSATIVO; se trataría de aquellos pasajes en los cuales el actante se comporta como paciente, frente a las acciones que ejecutan sobre él otros actantes dotados de potencia $<+>$. Estos últimos, a su vez, pueden asimilarse a un ERGATIVO; nos estaríamos refiriendo, en este caso, a los personajes que se presentan bajo el estatuto de causativo, tal como los presentamos en el análisis.

En el caso de los titulares de prensa, se pueden anotar las siguientes conclusiones. Los titulares de prensa focalizan los casos situados en la zona del evento. En la muestra seleccionada, los porcentajes referidos a los casos de la zona de la anterioridad y de la posterioridad no son significativos, lo cual indica que en los titulares de las páginas de sucesos interesa más la presentación del hecho que la indagación de las causas o la finalidad. También esto puede deberse al hecho de que los titulares -al igual que los encabezamientos-son, a menudo, el resumen de los acontecimientos principales de una información. Tanto el resumen como el acontecimiento principal pertenecen a las categorías obligatorias de una información periodística.

En los titulares y eslóganes de los anuncios publicitarios se privilegian las zonas del evento y la zona $\mathrm{C}$, correspondiente a los locativos. Esto nos indica que en el título del anuncio publicitario interesa la presentación del evento en el cual se va a centrar la acción del producto o servicio, pero que además, es importante cómo (LOC. NOCIONAL) el posible comprador puede obtener el beneficio. El hecho de que la tercera zona en importancia sea la zona de la posterioridad, donde está situado el FINAL, señala una de las características del discurso publicitario: presentar los posibles resultados o beneficios del producto o servicio. Puede también establecerse una diferencia entre los titulares de prensa y los títulos de los anuncios publicitarios. En los primeros la tercera zona focalizada es la zona B1 y en los segundos la zona B2. Esto está en relación con las características de cada discurso: a la noticia de prensa le interesan las causas de los hechos, mientras que 
a la publicidad -como ya se anotó- le interesa resaltar el posible beneficio que lograría el eventual comprador con la utilización del producto o servicio.

Los resultados de la investigación permiten afirmar que cada uno de los ejemplos utilizados en el corpus focaliza una determinada zona caso-conceptual. Las figuras 5, 6 y 7 muestran la diferencia entre las zonas caso-conceptuales que focalizan el relato, los titulares de prensa y los títulos y eslóganes de los anuncios publicitarios.

Por último, cabe señalar que el modelo que presenta las zonas caso-conceptuales se muestra adecuado para el análisis de los actantes tanto en titulares como en unidades de mayor complejidad discursiva, como es el caso del relato.

\section{Notas}

1. El presente trabajo fue leído como ponencia en el XI Congreso de la Asociación de Lingüística y Filología de la América Latina (ALFAL), que se celebró en julio de 1996 en la Universidad de Las Palmas, Gran Canaria, España.

\section{Bibliografía}

Desclés, J.P. 1994. "Relations Casuelles et Schèmes Sémantico-Cognitifs". Langages. 113: 113-125. París.

Fillmore, 1968. The Case for Case en Bach E., Harms R. (eds.). Universals in Linguistic Theory. London: Holt, Rinehart, Winstons. 1-88.

Harris, Z. 1963. Discourse Analysis Reprints. La Haya: Ed. Mouton.

Hjelmslev, L. 1978. La Categoría de los Casos. Madrid: Ed. Gredos.

Jackendoff, R. 1990. Semantic Structures. Cambridge (Mass.): MIT Press.

Jakobson, R. 1957. "The relationship between Genitive and Plural in the Declension of Russian Nouns." Scando-Slavica. T. III: 181-186.

Jusayú, M. 1986. Achi'kí. Relatos Guajiros. Caracas: UCAB.

Jusayú, M. 1994. "Relato de un Hombre cuya Mujer Murió." Opción. 15: 113-67. Maracaibo, Venezuela.

Molero de C. L. 1991. "Noémica y Semántica en un Relato Guajiro." Opción. 11: 27-46. Maracaibo, Venezuela.

1993. "Fundamentos de una Clasificación del Relato Guajiro." Opción. 12: 125-138. Maracaibo, Venezuela. 
1994. "Secuencias y Funciones en un Relato Guajiro." Opción. 15: 93-112. Maracaibo, Venezuela.

Perrin, M. 1979. Sükuaitpa Wayuu. Los Guajiros: la palabra y el vivir. Caracas: Fundación La Salle.

1980. El Camino de los Indios Muertos. Caracas: Monte Avila Editores, C.A.

Pottier, B. 1987. Théorie et Analyse en Linguistique. París: Hachette Université. 1992. Teoría y Análisis en Lingüística. Madrid: Ed. Gredos. 1993. Semántica General. Madrid: Ed. Gredos.

Van Dijk, T. 1990. La Noticia como Discurso. Barcelona: Ed. Paidós. 